\title{
Ranking and Aggregation of Factors Affecting Companies’ Attractiveness
}

\author{
Zoumpolia Dikopoulou \\ Faculty of Computer Science \\ Hasselt University \\ Diepenbeek, Belgium \\ zoumpolia.dikopoulou@student.uhasselt.be
}

\author{
Elpiniki Papageorgiou \\ Department of Computer Engineering \\ Technological Education Institute of Central Greece \\ Lamia, Greece \\ epapageorgiou@teiste.gr
}

\author{
Gonzalo Nápoles \\ Department of Computer Sciences \\ Central University of Las Villas \\ Santa Clara, Cuba \\ gnapoles@uclv.edu.cu \\ Koen Vanhoof \\ Faculty of Business Economics \\ Hasselt University \\ Diepenbeek, Belgium \\ koen.vanhoof@uhasselt.be
}

\begin{abstract}
Today, more and more businesses are growing constantly trying to stand and maintain in the forefront of their competitive advantage by devising various ways to satisfy their customers or even to create a better "image" to make the company more attractive not only to the consumers but also to the future employees. The difficulty in this case is not the collection of the participants' preferences, but how the conducted knowledge will be reflect better the participants' consensus. Therefore, based on the above, each company will be more competitive, if the factors that influenced the company will be improved. In this paper, Factor Analysis was performed to ascertain which of the given factors are the most important. Then, Technique for Order Preference by Similarity to Ideal Solution (TOPSIS) was used to rank and find the most significant factors that influence the public opinion when they are searching for a job, without expert knowledge. Two other Multi-criteria Decision Making methods the Weighted Sum Model (WSM) and Sum Ranking System (SRS), were considered to rank the factors and then all ranking results were compared. Finally, an aggregation of all evaluations was accomplished, extracting the people consensus.
\end{abstract}

Keywords- rankings; aggregation; MCDA; WSM; TOPSIS.

\section{INTRODUCTION}

The rapid developments in business sector entails with a continuous increase of complexity in right decision making when a variance of factors is taken into account. The decision factors could be associated with economic, social, psychological, environmental and political considerations. Most often it is difficult to identify and fully understand of these factors [1]. Wherefore, a very important category to support decision makers is Multi-criteria decision-making (MCDM).

The purpose of MCDM is to select the most important alternative in which the most important alternative is signified as the best overall value [2]. Standard ranking systems are a) Weighted Sum Model (WSM) which is constructed using point scores (weights) not produced randomly but are based on $1-\mathrm{N}$ point scale, where $1=$ not important and $\mathrm{N}=$ very important and b) Sum and Mean rankings without using any point scores.

Some of the criteria used to select business type using MCDM models including a single decision maker are presented in [3]. In particular, they propose the use of three deterministic families of models: WSM, WPM and analytic hierarchy process (AHP). Triantaphyllou and Baig, studied the use of four key MCDM methods, the weighted sum model, the weighted product model, and the AHP along with some of its variants, including the multiplicative AHP) for dealing with incompatible criteria. When the number of alternatives was high, the contradiction rates in these rankings became more dramatic and significant and proved that the multiplicative AHP was immune to these ranking inconsistencies. Furthermore, another method which belongs in MCDM family, the Technique for Order Preference by Similarity to Ideal Solution (TOPSIS) method is developed in this paper to estimate the best value of alternative $i$, with a finite number of criteria. TOPSIS was originally proposed by Hwang and Yoon (1981) and has received great interest from researchers and practitioners.

In TOPSIS methodology, the third most popular place takes the Business and Marketing Management (approximately $12.3 \%$ of all papers come under in this category) after Supply Chain Management, Logistics and Design, and Engineering and Manufacturing Systems which take the first and the second place, respectively [7]. In this field, issues like organizational performance, financial measurement, investment projects, customer satisfaction and competitive advantages are justified with TOPSIS. An algorithm was introduced to determine the most preferable choice among all possible choices to compare 15 bank branches in Iran based on financial ratios, when data was interval [8]. Chang, Lin, Lin, and Chiang (2010) proposed the extended TOPSIS method with different distance 
approaches to evaluate the performance of 82 Taiwanese mutual funds for almost three years. Three rankings methods [9], TOPSIS, PROMETHEE and VIKOR were used to evaluate classification algorithms for financial risk prediction using an empirical study that was designed to estimate the rankings. Fuzzy TOPSIS and rough AHP were proposed in [10] to evaluate the performance of four aviation firms, taking into account both quantitative and qualitative factors and the interrelations between them using five important criteria: performance risk, quality, effectiveness, efficiency and occupational satisfaction.

In this paper, three MCDM methods, the Sum Ranking System (SRS), the Weighted Sum Model (WSM) and the TOPSIS were used to rank the factors and find the most significant ones that influence the consensus which operates like an input to companies to improve the attractiveness. Due to the lack of criteria, a different approach of TOPSIS was applied with very promising results. The data in this problem are real and relevant to all companies which are resident in Belgium.

The rest of the paper is organized as follows: the next section describes the Weighted Sum Model and the steps of TOPSIS. In Section III, the real problem and the limitations are described. In Section IV, Factor Analysis and MCDM are used to find the important factors and calculate the rankings. Finally, the rankings are aggregated into two final rankings and the results are discussed. Section VI briefly describes the results and which is the impact in business community.

\section{METHODS}

\section{A. Weighted Sum Model (WSM)}

The well-known and simplest MCDA method for evaluating a number of alternatives $m$ in terms of a number of decision criteria is the Weighted Sum Model (WSM) (Triantaphyllou, 1997). Let's consider the eventuality that all $n$ decision criteria are benefit criteria, it is resulted that it is better when the values are higher. The relative weight of importance of the criterion $C R_{j}$ defined by $w_{j}$ and the performance value of alternative $A_{i}$ when it is evaluated in terms of criterion $\mathrm{CR}_{\mathrm{j}}$ is defined by $a_{\mathrm{ij}}$. The preference value ( $\mathrm{A}_{\text {WSM }}^{*}$ ), for $i=1,2, \ldots, m$, is denoted as the best alternative and is defined as:

$$
A_{W S M}^{*}=\max _{i} \sum_{j=1}^{n} a_{i j} w_{i j}
$$

The weights $\mathrm{W}=\left[\mathrm{W}^{1}, \mathrm{~W}^{2}, \ldots, \mathrm{W}^{\mathrm{n}}\right]$ are necessarily to prove the preference value. If they are not assigned by experts, they must be calculated, applying the basic methods of the convex analysis. The weight $\mathrm{W}^{1}=[1,0,0, \ldots, 0]$ corresponds to the alternative that the highest importance, the weight $\mathrm{W}^{2}=[1 / 2,1 / 2,0, \ldots, 0]$ corresponds to the alternative with the second highest importance and weight $\mathrm{W}^{\mathrm{n}}=[1 / \mathrm{n}, 1 / \mathrm{n}, \ldots, 1 / \mathrm{n}]$ corresponds to the alternate with the lowest importance.

\section{B. Technique for Order Preference by Similarity to Ideal Solution (TOPSIS)}

Technique for Order Preference by Similarity to Ideal Solution (TOPSIS) is one of many approaches of MCDM [6] in order to solve real-world decision problems. It flows from the concept of selected best alternative (or ranking the alternatives) that has the shortest distance from the positive ideal solution (PIS) and the farthest from the negative ideal solution (NIS) in a geometrical (Euclidean) sense. In TOPSIS method, all alternatives are considered simultaneously regarding the distances to both PIS and NIS. The ideal and non-ideal solutions are worked out by using normalized matrix. Next, the Euclidean alternative distances from the ideal and non-ideal point are calculated and relative closeness to the ideal solution is obtained which is in range of zero to one. TOPSIS uses $m$ alternatives (options) and $n$ attributes/criteria and gets as input the score of each option with respect to each criterion. In TOPSIS method, the importance of every index is not equal, so they must be set different weights factors [11]. The weight factors are very important because they directly influence the results of output and in many cases they were determined by the experts. Below, the method is organized as 7 steps:

Step 1: Create the decision matrix $D$ by each decision maker. Where $a_{i}$ indicates the $i t h$ alternative, $i=1,2, \ldots, m$; $C R j$ typifies the $j t h$ criterion/attribute, $j=1,2, \ldots, n ; x_{i j}$ represents the performance of the ith alternative as regards $j$ th criterion which correspond to an integer in range $1-9$, (Table I). Criteria $C R_{j}$ may be of benefit or cost type. Benefit type criteria means that the larger value of attribute is, the greater performance it has (represented by $\mathrm{J}^{+}$) while cost type criteria means that the smaller value of attribute is, the greater performance it has (represented by $J$ ).

TABLE I. MATRIX D WITH SIZE $\mathrm{M}^{*} \mathrm{~N}$

\begin{tabular}{|c|c|c|c|c|}
\hline \multirow{2}{*}{ Alternatives } & \multicolumn{4}{|c|}{ Criteria } \\
\cline { 2 - 5 } & $C R_{1}$ & $C R_{2}$ & $\cdots$ & $C R_{n}$ \\
\hline$a_{1}$ & $x_{11}$ & $x_{11}$ & $\cdots$ & $x_{11}$ \\
\hline$a_{2}$ & $x_{21}$ & $x_{22}$ & $\cdots$ & $x_{21}$ \\
\hline & & & & \\
\hline$a_{m}$ & $x_{m 1}$ & $x_{m 2}$ & $\cdots$ & $x_{m n}$ \\
\hline
\end{tabular}

Step 2: Normalize the decision matrix to transform various attribute dimensions into non-dimensional attributes, which allows comparisons across criteria. The $R$ represents the square root of the addition element value squares, according to each criterion. The $R$ is calculated for each $j$ criterion of decision making matrix.

$$
R_{j}=\sqrt{\sum_{i=1}^{m} x_{i j}^{2}}
$$

for $i=1, \ldots, m ; j=1, \ldots, n$.

Then, divide each column by to get $r_{i j}$ which represents the elements of new normalized decision making matrix and calculated below as: 


$$
r_{i j}=x_{i j} / \sqrt{\sum_{i=1}^{m} x_{i j}^{2}}
$$

for $i=1, \ldots, m ; j=1, \ldots, n$.

Step 3: Calculate weighted normalized decision matrix by multiplying each column of the normalized decision matrix with normalized weight coefficients $w_{j}$, for $j=1, \ldots$, $n$, such as that: $\sum_{j=1}^{n} w_{j}=1$. The weight normalized value $\mathrm{v}_{i j}$ is calculated as:

$$
v_{i j}=w_{j} r_{i j}
$$

Step 4: Specify the ideal and non-ideal points. Ideal point:

$$
\begin{aligned}
& A^{+}=\left\{\left(\max _{i} v_{i j} \mid j \in J_{1}\right),\left(\min _{i j} \mid j \in J_{2}\right) \mid i=1,2, \ldots, m\right\}= \\
& =\left\{v_{1}^{+}, v_{2}^{+}, \ldots, v_{j}^{+}, \ldots, v_{n}^{+}\right\}
\end{aligned}
$$

Non-ideal point:

$$
\begin{aligned}
& A^{-}=\left\{\left(\min _{i} v_{i j} \mid j \in J_{1}\right),\left(\max _{i j} \mid j \in J_{2}\right) \mid i=1,2, \ldots, m\right\}= \\
& =\left\{v_{1}^{-}, v_{2}^{-}, \ldots, v_{j}^{-}, \ldots, v_{n}^{-}\right\}
\end{aligned}
$$

Whereas $J_{1} \subset\{1,2, \ldots, n \mid j-\max \}$ for the max type criteria and $J_{2} \subset\{1,2, \ldots, n \mid j-\min \}$ for the min type criteria.

Step 5: Calculate the Euclidean distances of each alternative $a_{i}$ from the ideal point $A^{+}$and of each alternative $a_{i}$ from the negative ideal point $A^{-}$:

$$
\begin{aligned}
& S_{i}^{+}=\sqrt{\sum_{j=1}^{n}\left(v_{i j}-v_{j}^{+}\right)^{2}} \text { and } S_{i}^{-}=\sqrt{\sum_{j=1}^{n}\left(v_{i j}-v_{j}^{-}\right)^{2}} \\
& i=1, \ldots, m .
\end{aligned}
$$

Step 6: Calculate the relative closeness of the alternatives from ideal and non-ideal points. If $C_{i}$ is equal to 1 then $a_{i}$ is the ideal point $\left(A^{+}\right)$and if $C_{i}$ is equal to 0 then $a_{i}$ is the negative ideal point $\left(\mathrm{A}^{-}\right)$.

$$
C_{i}=\frac{S_{i}^{-}}{S_{i}^{+}+S_{i}^{-}} ; 0 \leq C_{i} \leq 1 ; i=1, \ldots, n
$$

Step 7: Rank alternatives according to $C_{i}$ and select the alternative with maximum $C_{i}$.

\section{PROBLEM DEFINITION}

In our case study, we collected 14.585 questionnaires from people in Belgium, aged between 18 to 65 years, male and female from different level of education, working in different sectors. The questionnaires asked respondents to choose factors, listed in Table II, that they considered most significant in case they wished to employ in a company $\mathrm{X}$. The participants had no knowledge of the company's name.

The questionnaire was divided into two parts, Data Set 1 (DS1) and Data Set 2 (DS2). In DS1, participants chose only five of the seventeen factors that consider most important and gave their preference value. The values were ranged between 1 and 5 . The value "1" indicates that the $F_{i}$ factor is

\begin{tabular}{|c|c|c|c|}
\hline \multicolumn{4}{|c|}{ Factors } \\
\hline$F 1$ & Financially sound & F10 & $\begin{array}{l}\text { Good balance between } \\
\text { life and work }\end{array}$ \\
\hline$F 2$ & Offers quality training & F11 & Well located \\
\hline F3 & $\begin{array}{l}\text { Offers long-term job } \\
\text { security }\end{array}$ & F12 & $\begin{array}{c}\text { Strong image / pursues } \\
\text { strong values }\end{array}$ \\
\hline F4 & $\begin{array}{l}\text { Offers international / } \\
\text { global career }\end{array}$ & F13 & $\begin{array}{l}\text { Quality products / } \\
\text { services offered }\end{array}$ \\
\hline F5 & $\begin{array}{c}\text { Future prospects / } \\
\text { career opportunities }\end{array}$ & F14 & $\begin{array}{l}\text { Deliberately handles the } \\
\text { environment and society }\end{array}$ \\
\hline F6 & Strong management & F15 & $\begin{array}{l}\text { Uses the latest } \\
\text { technologies / } \\
\text { innovative }\end{array}$ \\
\hline F7 & $\begin{array}{l}\text { Offers interesting jobs } \\
\text { (job description) }\end{array}$ & F16 & $\begin{array}{c}\text { Provides flexible } \\
\text { working conditions }\end{array}$ \\
\hline F8 & $\begin{array}{c}\text { Pleasant working } \\
\text { environment }\end{array}$ & F17 & $\begin{array}{c}\text { Encourages diversity } \\
\text { (age, gender, ethnicity) }\end{array}$ \\
\hline F9 & $\begin{array}{c}\text { Competitive salary } \\
\text { package }\end{array}$ & & \\
\hline
\end{tabular}
the most important (and therefore the best factor of all 17 factors). The value " 5 " indicates that the $F_{i}$ factor is in the TOP 5 list, but ranked fifth according to the participant's discretion. Each participant selects five factors which evaluates them by giving five different values within the range of $[1,5]$.

TABLE II. THE 17 FACTORS WHICH WERE EVALUATED BY EACH RESPONDENT.

In DS2, participants didn't have any limitation for the factors' choice. The procedure for the selection of factors was very simple. Each participant had to split the amount of one thousand points to factors that they considered most important by giving more points to the most significant factor, with the restriction of choosing at least two factors, $2 \leq \operatorname{TOP}_{N} \leq 17$. In that data set, it is possible more than one factor has the same value.

\section{RESULTS AND DISCUSSION}

In this section, we present the conducted experiments in both data sets. The first procedure before rankings was to clean data and remove the outliers from this survey. The data with small standard deviation (less than 0.25 ) were removed in order to process the data better and achieve the best results. Factor Analysis was used in SPSS to find the meaningful factors using the Principal Component Analysis as the Extraction Method to get the Communalities of 17 factors. Once the extraction of factors has been completed, the table of "Communalities" inform us about the variance of each factor. Higher communalities are desirable. If the communality for a variable is less than 0.5 , it is a candidate for exclusion from the analysis because the factor solution contains less than half of the variance in the original variable, in other words these factors considered as at the least significant. Table III, describes the Communalities of the most significant factors (greater than 0.5) of DS1 and DS2 which are: $F_{1}, F_{2}, F_{3}, F_{4}, F_{5}, F_{7}, F_{8}, F_{9}, F_{10}, F_{11}$ and $F_{1}, F_{2}, F_{3}$, $\mathrm{F}_{5}, \mathrm{~F}_{7}, \mathrm{~F}_{8}, \mathrm{~F}_{9}, \mathrm{~F}_{16}$, respectively.

Even though factor analysis was accomplished as a first step of ranking, still remains the question about which of the 
significant factors are belonging in TOP-5 list. For this reason, three MCDA methods used (SRS, WSM and TOPSIS) to classify the factors. In this paper, the TOPSIS method does not use criteria, because there is no knowledge about criteria. The criteria replaced by the number of participants. The other two methods were used to compare the rankings with TOPSIS rankings. The classifications were performed in 15 sectors, in two data sets, DS1 and DS2. Finally, using TOPSIS, classifications were aggregated into a final ranking which represents the common opinion.

TABLE III. COMMUNALITIES HIGHER THAN 0.5 OF DS1 AND DS2.

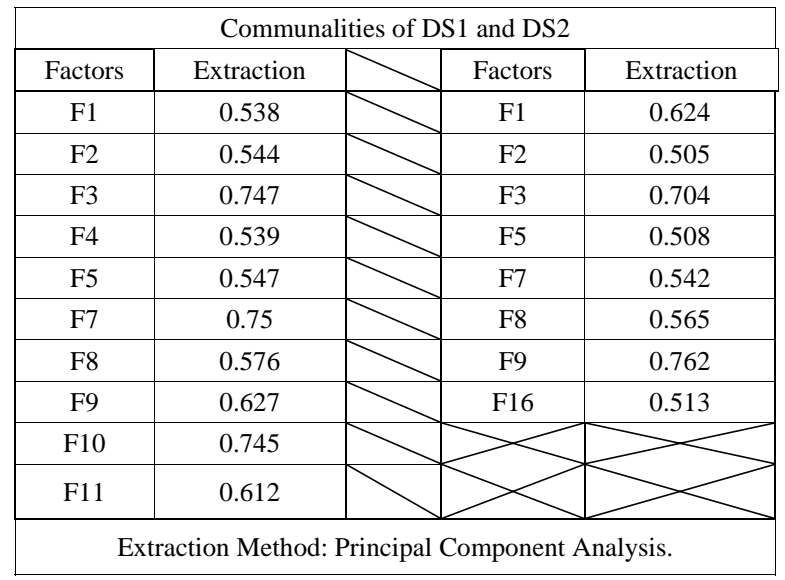

The next step to be accomplished was to classify the factors using the three MCDA methods: SRS, WSM and TOPSIS, (specifically the first five factors) which are the important factors as the Analysis of the Communalities shown.

In our problem, due to lack of criteria which are important to determine the TOPSIS ranking we customized the criteria (the columns of the matrix) and replaced them with the participants' opinion $\left(P_{1}-P_{14.585}\right)$ and the alternatives (rows of the matrix) replaced with the seventeen factors $\left(F_{1}-F_{17}\right)$. In TOPSIS method, no weights required because all participants had equal importance. The performance of the ith factor as regards $j$ th participant which correspond to an integer in range $1-9$ is represented by $x_{i j}$. So, the participants' estimations were initially normalized in range 1 - 9, as shown in Table IV.

TABLE IV. THE NEW FORM OF TOPSIS IN OUR PRBLEM.

\begin{tabular}{|c|c|c|c|c|}
\hline \multirow{2}{*}{ Alternatives } & \multicolumn{4}{|c|}{ Criteria } \\
\cline { 2 - 5 } & $P_{1}$ & $P_{2}$ & $\cdots$ & $P n$ \\
\hline$F_{1}$ & $x_{1,1}$ & $x_{1,1}$ & $\cdots$ & $x_{1, n}$ \\
\hline$F_{2}$ & $X_{2,1}$ & $X_{2,2}$ & $\cdots$ & $x_{2, n}$ \\
\hline & & & & \\
\hline$F_{17}$ & $X_{17,1}$ & $X_{17,2}$ & $\cdots$ & $X_{17, n}$ \\
\hline
\end{tabular}

Then, the ideal and non-ideal points were specified, according (6) and (7). Hence, the Euclidean distance and each factor/alternative from the ideal point $A^{+}$and the negative ideal point $A^{-}$were calculated, respectively in (8). The relative closeness (9) of the alternatives from ideal and non-ideal points were found and finally, the factors were ranking according to their maximum value of calculations.

In SRS, the total sum of factors was classified using the frequency table from the SPSS and the rankings applied for each factor for each sector in both data sets (DS1 and DS2). Two main components which compose the Weighted Sum Model (WSM) are the weights and the sum of relative values. The weights for the five summarized values [1, 5], $w=\left[\begin{array}{lllll}0.040 & 0.090 & 0.157 & 0.257 & 0.457\end{array}\right]$ were calculated according to (2) and applied to all 17 factors.

In this paper, all rankings of the 15 sections were studied and observed that the TOPSIS method without the use of criteria but taking account only the participants' evaluations is quite similar with the other two methods. Specifically, more similarities observed between the methods WSM and TOPSIS. Figures 1 and 2, compare the rankings of SRS, WSM and TOPSIS, which were applied in Finance Sector in DS1 and DS2, respectively. In DS1, the first five factors, $F_{3}>$ $\mathrm{F}_{9}>\mathrm{F}_{1}>\mathrm{F}_{7}>\mathrm{F}_{8}$ and in DS2, the first seven factors, $\mathrm{F}_{9}>\mathrm{F}_{3}>$ $\mathrm{F}_{1}>\mathrm{F}_{7}>\mathrm{F}_{8}>\mathrm{F}_{10}>\mathrm{F}_{11}$, are completely the same using the three MCDA methods and small differences are observed at the rest factors. Among the above two classifications, it is also observed that although the participants responded in two different ways in the questionnaires, strictly choosing five factors (DS1) and completely free to choose as many factors they desire (DS2), the top 5 factors remain at the top five places in rankings. Furthermore, the top 5 factors, in DS1 and DS2, were identified as significant in Analysis of the Communalities too (see TABLE III).

Since the TOPSIS method was proved effective in our problem to rank properly the factors, we applied once again TOPSIS method to aggregate the people consensus in the final classification. Fifteen rankings, (once for each sector) were used as an input to TOPSIS method and applied in DS1 and DS2 (Figure 3). In this case, the criteria were not replaced with participants (TABLE IV) but replaced with the sectors' ranking (Sector1 - Sector15) and the alternatives replaced with the seventeen factors (F1 - F17). As noted in the final standings the top five factors (the most significant factors), are common in both different data sets.

DS1: $\boldsymbol{F}_{\mathbf{3}}>\boldsymbol{F}_{\mathbf{1}}>\boldsymbol{F}_{\boldsymbol{7}}>\boldsymbol{F}_{\mathbf{9}}>\boldsymbol{F}_{\boldsymbol{8}}>F_{10}>F_{5}>F_{11}>F_{2}>F_{16}>$ $F_{4}>F_{6}>F_{13}>F_{12}>F_{17}>F_{15}>F_{14}$

DS2: $\boldsymbol{F}_{\boldsymbol{9}}>\boldsymbol{F}_{\mathbf{3}}>\boldsymbol{F}_{\mathbf{1}}>\boldsymbol{F}_{\mathbf{7}}>\boldsymbol{F}_{\boldsymbol{8}}>F_{11}>F_{10}>F_{5}>F_{16}>F_{2}>$ $F_{6}>F_{4}>F_{13}>F_{17}>F_{14}>F_{12}>F_{15}$.

The purpose of the final ranking was to aggregate the common opinion (or else the consensus). The rankings of Data Set 1 (participants choose only five factors) and Data Set 2 (participants choose as many factors) were very similar. The top five factor (F1 - Financially sound, F3 - Offers long-term job security, F7 - Offers interesting jobs (job description), F8 - Pleasant working environment and F9 Competitive salary package) which are in the top-5 of both data sets, reflect the significant factors that need to improve 
when the company $\mathrm{X}$ cares about the attractiveness or wants to enhance the competitive advantage.

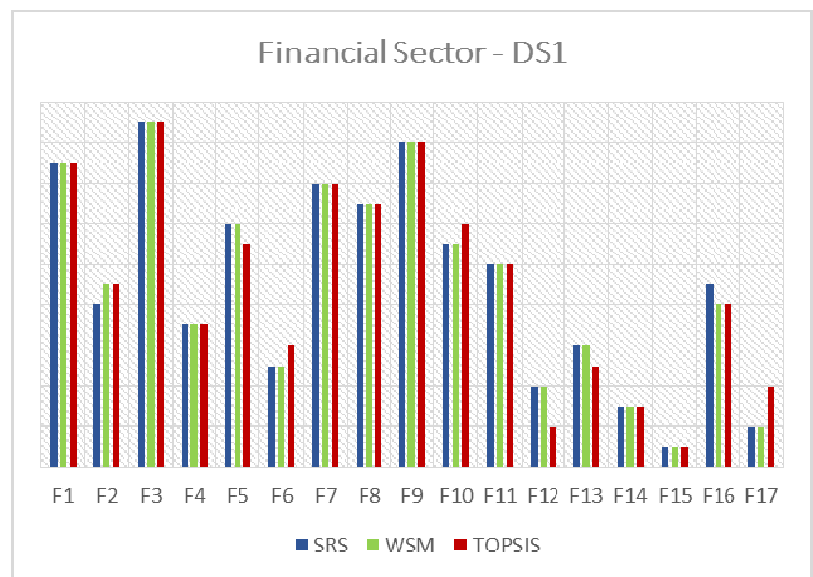

Figure 1. Rankings of three different MCDM methods in Financial Sector using the DS1.

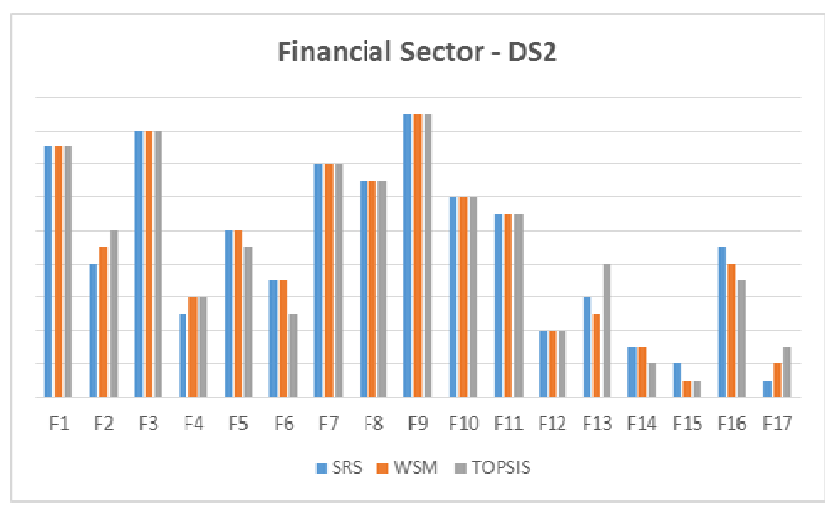

Figure 2. Rankings of three different MCDM methods in Financial Sector using the DS2.

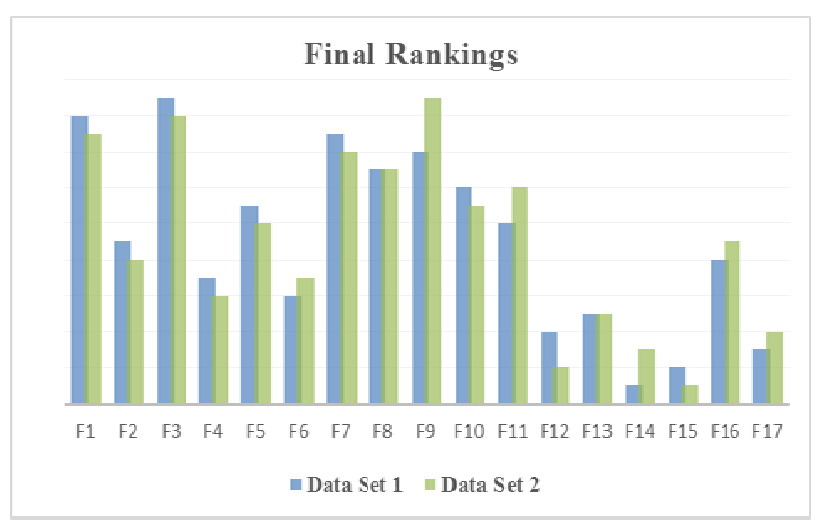

Figure 3. Final rankings of 17 factors using TOPSIS method.

The ranking of top 5 factors show that the people prefer long term job security and competitive salary package more than offering of interesting jobs, financially sound and pleasant working environment.

The produced results are encouraging to continue our efforts to this direction and further investigate the best factors that will help a company to increase its attractiveness by boosting employee satisfaction and thus help the company retain personnel and/or improve the brand name of the company which allows to increase the sales of their products or services.

\section{CONCLUSION}

From the data analysis it is concluded that the TOPSIS method aggregated with the other two, is the best variant when solving this kind of aggregation problems. It also showed that people in Belgium prefer stability (long-term security) instead of jobs financially sound. However, this outcome is not surprising and it could be a direct result of the economic crisis.

\section{REFERENCES}

[1] Roy, B, "Multiple criteria decision analysis: State of the art surveys," Springer Science and Business Media, 2005, pp. 3-24.

[2] Kelemenis A., Askounis D., "A new TOPSIS-based multi-criteria approach to personnel selection”, Expert Systems with Applications 37, 2010, pp. 4999-5008J..

[3] A. H. Ahmed, H. M. Bwisa, R. O. Otieno, Business Selection using Multi-Criteria Decision Analysis, International Journal of Business and Commerce, Vol. 1, No. 5: Jan 2012, pp. 64-81.

[4] E. Triantaphyllou, K. Baig, "The impact of aggregating benefit and cost criteria in four MCDA methods", IEEE Transactions on Engineering Management, 06/2005; DOI: 10.1109/TEM.2005.845221.

[5] S. Sitarz, "Mean value and volume-based sensitivity analysis for Olympic rankings”, European Journal of Operational Research 216, 2012, 232-238.

[6] Hwang and Yoon Hwang, "Multiple attribute decision making: Methods and applications”. New York: Springer-Verlag., 1981.

[7] Majid B., S. Khanmohammadi O., Morteza Y., Joshua I., “A state-of the-art survey of TOPSIS applications", Expert Systems with Applications 39, 2012, pp. 13051-13069

[8] Jahanshahloo, G. R., Lotfi, F. H., \& Izadikhah, M., "An algorithmic method to extend TOPSIS for decision-making problems with interval data”, Applied Mathematics and Computation, 175, 2006, pp. 1375-384.

[9] Peng, Y., Wang, G., Kou, G., \& Shi, Y., “An empirical study of classification algorithm evaluation for financial risk prediction. Applied Soft Computing”, 11, 2011, pp. 2906-2915.

[10] Aydogan, E. K., "Performance measurement model for Turkish aviation firms using the rough-AHP and TOPSIS methods under fuzzy environment”. Expert Systems with Applications, 38, pp. 39923998.

[11] A.T. Balafoutis, E. Papageorgiou, Z. Dikopoulou, S. Fountas, G. Papadakis, "Sunflower oil fuel for diesel engines: Experimental investigation and optimum engine setting evaluation using MCDM approach”, International Journal of Green Energy, 2014, 642-673.

[12] Chang, C. H., Lin, J. J., Lin, J. H., \& Chiang, M. C., "Domestic openend equity mutual fund performance evaluation using extended TOPSIS method with different distance approaches", Expert Systems with Applications, 37, 2010, 4642-4649. 